\title{
Larvicidal Efficacy of Crude Essential Oil (Leaf Extracts) of Pyrethrum (Chrysanthemum: Compositae), Eucalyptus camaldulensis Sm (Myrtaceae) and Nicotiana tabaccum (Tobacco L.) (Solanaceace) against Third Instar Larvae of the Malaria Vector Anopheles gambiae s.s. Giles (Diptera: Culicidae)
}

\author{
Glenn O. Araka (M. Sc, Lead Researcher ) ${ }^{1}$, John Ochora (PhD) ${ }^{2}$, Johnstone Wakhisi (PhD) ${ }^{3}$ \\ ${ }^{1}$ Lecturer, Department of Environmental Health, School of Public Health, Moi University, Eldoret, Kenya \\ ${ }^{2}$ Professor, Department of Botany, School of Biological Sciences, Jommo Kenyatta University of Agriculture and Technology ( JKUAT ), \\ Nairobi, Kenya
}

${ }^{3}$ Professor, Department of Medical Biochemistry, Moi University, Eldoret, Kenya

\begin{abstract}
In this study crude leaf extract of Pyrethrum, Eucalyptus camaldulensis and Nicotiana tabaccum (Tobacco) were tested for their larvicidal activity against Anopheles gambiae s.s. Giles (Diptera: Cidicidae), a member of Anopheles gambiae complex. Six different solvents were used namely ethanol, methanol, dichloromethane (DCM), hexane, ethyl acetate and water (aqueous) for the preparation of crude extracts from the plant leaves. The larval mortality of the late third instar larvae of Anopheles gambiae s.s Giles after 24 hour of exposure were observed separately in control at 50,100,150,200,250,300, 350 and 400 ppm concentrations of the leaf extract. The six different solvent extract of the plants showed good larvicidal activity. The highest potency was recorded by DCM extract of Pyrethrum $\left(L C_{50}, 164.68 \mathrm{ppm}, L C_{90} 255.17 \mathrm{ppm}\right)$ achieving $100 \%$ mortality of the third instar larvae. In a similar response the DCM extract of Eucalyptus camadulensis recorded second highest activity at $L C_{50} 168.65$ ppm and $L C_{90} 315.85$ ppm causing a mortality of 100\% .Ethanol extract of pyrethrum exhibited high larvicidal activity at 167.78 ppm against third instar larvae of An. Gambiae s.s.than same extracts of Nicotiana tabaccum (189.58 ppm) and Eucalyptus camaldulensis (210.15 ppm). The rest of the extracts i.e. methanol, hexane, ethyl acetate and aqueous exhibited a range of varying activities from $197.46 \mathrm{ppm}$ (methanol) to $260.56 \mathrm{ppm}$ (ethyl acetate). There was no mortality observed in controls. A general observation made was that the third instar larvae were susceptible to all treatments. The larvicidal activity of the treatments were dose and time independent and all of the volatile oils showed significant larvicidal activity against Anopheles gambiae s.s. Giles larvae after 24 hours exposure. The $L^{C_{50}}$ and $L_{90}$ with their 95 percent confidence limits of the oils were determined using log probit analysis test (Finney, 1971) (1). From these results it was observed that the leaf extract of pyrethrum contain toxic compounds to mosquito larvae and therefore suggest that pyrethrum extract has potential in the control of the malaria mosquito and can be developed and used. Further studies of these plants as possible agents for mosquito control are recommended.
\end{abstract}

Keywords: Pyrethrum, Eucalyptus camaldulensis, Nicotiana tabaccum (Tobacco), Anopheles gambiae s.s., Anopheles gambiae complex, solvents, crude leaf extract, concentrations, log probit, mortality, larvicidal activity, dose independent.

\section{Introduction}

Amongst the six members of Anopheles gambiae complex which are competent in the transmission of malaria in subSaharan Africa two sibling species namely Anopheles gambiae s.s. and Anopheles arabiensis (Diptera:Culicidae) are the most widely distributed and best known as malaria transmitters and sub-Saharan Africa suffers by far the greatest malaria burden worldwide (Bryrne, 2007) (2).

Mosquitoes act as vector for most of the life threatening diseases such as malaria, yellow fever, dengue fever, chikungunya fever, filariasis, encephalitis, west Nile virus infection and other more (3). Efforts are made in the prevention and control of malaria vectors in the affected regions by application of appropriate use of chemical insecticides in the field and indoor spraying of insecticides. Of important use is also the eradication of adult mosquitoes by long lasting insecticidal treated nets (LLINS), a method found to act both as preventive and control approach. It is observed that reiterated application of chemical insecticides has the negative effect of developing resistance in malaria vectors (3)(4).

Besides this chemical insecticides have the properties of environmental persistence, are also unbiodegradable and toxic. A good number of them tend to bioaccumulate in fact tissues of organisms consequently becoming carcinogenic, teratogenic, mutagenic and allergenic (5). For this reason there is great need for the alternative strategies for the malaria vector control of which plant extracts seem to take lead as good products for vector control, especially in view 


\section{International Journal of Science and Research (IJSR) \\ ISSN (Online): 2319-7064 \\ Index Copernicus Value (2013): 6.14 | Impact Factor (2014): 5.611}

of the fact that these natural products are biodegradable, non-toxic and do not bioaccumlate in fat tissues of organisms. They may not develop resistance in vectors, however, if they do will be slow (6).

Pyrethrum is the most widely used botanical insecticide. It is derived from the flowers of a plant in the genus Chrysanthemum (Tanacetum), which belongs to the family Compositae. This genus contains many species of which only a few (e.g C. reseum and C. cinerariaefolium) produce insecticidal substances which have been exploited at one time or other. Most of the world's supply of pyrethrum and C. cinerariaefolium comes from Kenya, which produces the most potent flowers (Moore and Levy, 1975) (7). Pyrethrin as an insecticide in Kenya has been used in its solid (mosquito coils), powder and liquid forms to control insect vectors, however, scientific information on its application on mosquito control is not documented other than Sulaiman et al., (2001) (8) who have conducted laboratory bioassay on Dengue/Dengue haemorrhagic fevers and Chagas disease (Allan and Milley 1990) (9).

Eucalyptus is a diverse genus of flowering trees (and a few shrubs) in the myrtle family, Myrtaceae, members of the genus dominate the tree flora of Australia. There are more than 700 species of eucalyptus mostly native to Australia and a very small number are found in the adjacent areas of New Guinea and Indonesia and are as far as north as the Philippine archipelago and Taiwan (Blakely, 1965; Benett, 2010) (10)(11). Only 15 species occur outside Australia, and only 9 do not occur in Australia. However, eucalyptus are cultivated throughout the tropics and sub-tropics including the Americas, Europe, Africa, the Mediterranean Basin, the Middle East, China and the Indian subcontinent (Gledhil,2008)(12); (en.wikipedia.org/wiki/Eucalyptus. Retrieved 13.10.2011. Eucalyptus have many uses which include soil drainage to reduce malaria and the oil of various eucalyptus species stands best investigated amongst the three oils of this study on various mosquito species: Ramar et al., (2014) (13), Ghosh et al., (2012) (14 ), Medhi et al., (2010) (15), Escatin and Mariani (2014) (16), Bilal et al., (2012) (17), Taher et al., 2012 (18), Bossou et al., (2013) (19), Navenahiran et al., (2014) (20), Tandon and Anita (2014) (21), Uthayarasa et al., (2010) (22), Abdullahi and Singh (2014) (23), Wada, A. (2014), (23), Karthikiyan et al., (2012) (24), Hazrat et al., (2012) (25) Pugazhvendan et al., (2013) (26) Cheng et al., (2009) (27), Nair et al., (2014) (28) and Sengottyan Senthil Nathan (2007) (29) among others.

The word tobacco may refer either to the various species of broad-leafed plants comprising the genus Nicotiana of the nightshade family or to the dried leaves of these plants. There are more than 70 species of tobacco, of which 45 are native to the Americas (http://www.lycos.com/info/tobaccoplants (30), retrieved March 4.2015). Nicotiana tabaccum is not found wild and may be hybrid of other species. In consumption it most commonly appears in the forms of smoking (cigarettes or pipe), cigars, chewing, snuffing, or dipping tobacco, or snus/snuff, (http://en.wikipedia.org/wiki/tobacco\#cite-ref 1(31), retrieved March 4,2014. The poisoning principle in tobacco is an alkaloid nicotine, which in the pure state is a colourless fluid, slightly heavier than water. "Black leaf" is a concentrated tobacco extract containing 40\% nicotine sulphate and is used at strengths varying from one part in 800 parts of water to one part in 1600 parts to kill insect vectors of disease. Nicotiana rustica (wild tobacco) contains about 10 times the nicotine of $N$. tabaccum (http://en.wikipedia.org/wiki/Tobacco\#cite-ref1 (32), retrieved March 4,2015. The leaf extract of Nicotiana tabaccum has been tested against mosquito larvae and have shown excellent results (Olofintoye et al., 2011) (33) , Puripattanavong et al., (2013) ( 34), Ru et al., (2012) (35), Priyanka et al., (2013) (36) , In these bioassays it has been demonstrated that concentration of essential oils is inversely related to mortality time. This association could be due to the increase of uptake of active ingredients by mosquitoes (Kabir et al., 2003) (37). In these earlier tests (13-29) it was observed that when mosquitoes were exposed to higher concentrations for 5-30 minutes, almost all showed signs of paralysis lying at the bottom of the bottle. But the modes of actions of plant products could be different from the existing insecticides for vectors control (Mcallister and Adams, 2010) (38).

\section{Materials and Methods}

\subsection{Collection of plant materials and extraction of essential oils}

A total of three plants were selected for use in these tests and were collected from various sources in Kenya in the month of May 2015. Pyrethrin (1 litre) as crude extract was purchased from Pyrethurm Board of Kenya (PBK), Stanley Mathenge Road, Nakuru, Kenya as a reserve extract. From the same Board $5 \mathrm{~kg}$ of dried pyrethrum flowers were as well purchased to be able to extract crude oil using similar solvent as those for Eucalyptus camaldulensis and Nicotiana tabaccum. PBK is a pyrethrum processing and marketing industry located 98 miles $(156.8 \mathrm{~km})$ east of Eldoret municipality and similar distance west of Kenya capital city, Nairobi. Eucalyptus leaves from mature gum trees (Eucalyptus camaldulensis) were collected from Molo subcounty, Kenya a distance of 68 miles $(108.8 \mathrm{~km})$ east of Eldoret and 30 miles (48 km) west of Nakuru. Tobacco leaves from the tobacco plant Nicotiana tabaccum were purchased from Mr. Meshack Wasike tobacco farm in Malakisi Location, Bungoma county, Kenya, a distance of 88 miles $(140.8 \mathrm{~km})$ west of Eldoret municipality and 15 miles $(24 \mathrm{~km})$ to the boarder of Kenya and Uganda. Pyrethrum which was purchased from $\mathrm{PBK}$ and extracted as crude oil using hexane was stored at $4^{0} \mathrm{C}$ in airtight amber or blue bottle until later when required for use. The dried pyrethrum flowers (Compositae cinerariaefolium one grown in Kenya) was extracted for pyrethrin mechanically using a commercial stainless steel blender, then $1 \mathrm{~kg}$ of powdered leaves was mercerated using six nonpolar to polar solvents: dicholomethane (DCM), ethyl acetate, ethanol, methanol, hexane and aqueous and similarly were stored under $4^{0} \mathrm{C}$ until required for use. The leaves of Eucalyptus camaldulensis, and Nicotiana tabaccum (2kg each) were dried in shed for 20-30 days. The dried leaves were then separately powdered mechanically by the same commercial electrical stainless steel blender. One $\mathrm{kg}$ of each powdered leaves was extracted successfully by merceration using six nonpolar to polar solvents namely hexane, dicholoromethane 


\section{International Journal of Science and Research (IJSR) \\ ISSN (Online): 2319-7064 \\ Index Copernicus Value (2013): 6.14 | Impact Factor (2014): 5.611}

(DCM), ethyl acetate, ethanol, methanol and water (aqueous). In each solvent the plant material was soaked for 48 hours at $35^{\circ} \mathrm{C}$ and filtered twice first using a fine cloth and then using Whatman number 1 filter paper $(12 \times 15 \mathrm{~cm})$ to obtain the extract and to the residue the same solvent was added again. The procedure was repeated twice to obtain maximum extract. The extracts were concentrated at reduced temperature using a rotary vacuum evaporator and stored in air tight amber or blue bottles at $4^{0} \mathrm{C}$ until when required for use.

From the stock solutions of the extracts, varying concentrations of each extract were prepared and these concentrations were used for larvicidal bioassays. All chemicals used in this study were of extreme pure grade obtained from Kenya Medical Research Institute (KEMRI), Kisumu, Kenya.

\subsection{Mosquito Collection}

Larvae of Anopheles gambiae s.s. Giles mosquito were grown in a laboratory ( insectary) at the Human Anatomy Department, School of Medicine, Moi University, Eldoret. Using a mouth aspirator, male and female adult Anopheles gambiae s.s. Giles mosquitoes were collected into test tubes from Langas sub-urban area and taken for rearing in the laboretory. The mosquitoes were placed in cages (30 x $30 \mathrm{x}$ $30 \mathrm{~cm}$ ) in the ratio 3:1 male:female and were fed on $10 \%$ sucrose solution soaked in cotton wool. The rearing was carried out at a temperature of $27 \pm 2{ }^{0} \mathrm{C}$ and $70-80 \%$ Relative Humidity (RH). The larvae were maintained under favourable conditions of larval rearing (temperature $27 \pm 2^{0} \mathrm{C}$, RH 70-80\%. Larvae were fed in the laboratory with brewers yeast, dog biscuits and algae (3:1:1) on water surface.

\subsection{Larvicidal bioassays}

Larvicidal activity of each extract derived from the leaves of Pyrethrum, Eucalyptus camaldulensis and Nicotiana tabaccum (Tobacco) were tested. The test medium (250ml glass beakers) was prepared by adding $1 \mathrm{ml}$ of appropriate dilution of essential oil in ethanol and mixed with $249 \mathrm{ml}$ of distilled water to make up $250 \mathrm{ml}$ of test solution (Dhamagadda et al, 2005) (39). Note that as the essential oil does not dissolve in water, it was first dissolved in ethanol (99.0\%). From the standard solution varying concentrations of each extract by dilution with distilled water, was prepared in various concentrations of 50, 100, 150, 200, 250, 300, 350 and $400 \mathrm{ppm}$ and these concentrations were used for larvicidal bioassays (An alternative to this method is to take
$1 \mathrm{gm}$ of the concentrated plant extract and dissolve in $100 \mathrm{ml}$ of 1:1 acetate: diethyl sulphoxide (DMSO) and consider as $1 \%$ stock solution. From this stock solution varying concentrations as indicated above but expressed as percent could be prepared for use in larvicidal bioassays).

Third instar of Anopheles gambiae s.s. Giles were exposed to these broad range of test concentrations of each leaf extract to determine the activity range of each extract. Susceptibility tests were carried out using WHO insecticide susceptibility test-kits (however, slightly modified) and standard procedures (1981) (40). The laboratory reared $\left(27 \pm 20^{\circ} \mathrm{C}\right.$ and $\left.75 \pm 5 \% \mathrm{RH}\right)$ late third instar larvae of Anolpheles gambiae s.s. Giles were used for experiments. By use of a mouth aspirator batches of 25 late third instar larvae were transferred to $300 \mathrm{ml}$ wide mouth disposable bowls containing serial concentrations of each plant extract. Four replicates were performed for each concentration. Larvae were confirmed dead when they failed to move after probing them with a needle at their cervical region. Moribund larvae were those incapable of rising to the surface when the test solutions were disturbed gently. Moribund larvae were counted after 24 hours of exposure (and added to dead larvae WHO, (2005) (41) and percentage mortality was calculated for each test as follows:-

Number of dead larvae $\div$ Number of larvae introduced $\times$ 100.

The final percentage was calculated from the average of four replicates. Solutions containing unchlorinated tap water and 1:1 v/v acetone: DMSO but without the plant extract, served as controls. The control mortalities were corrected by using Abbott's formula (1925) (42).

\subsection{Statistical Analysis}

The average larval mortality data were subjected to Probit analysis for calculating $\mathrm{LC}_{50}$ and $\mathrm{LC}_{90}$ and other statistics at 95\% fiducial limits of upper confidence limits (UCL) ad lower confidence limit (LCL) and chi-square values were calculated using the SPSS 18.0 (Statistical Package of Social Sciences) software - Finney,( 1971) (1).

\section{Results}

The results of larvicidal efficacy are shown in Table 1 . The results showed that all the

Table 1: Larvicidal efficacy of crude oil (leaf extracts) of Pyrethrum (Compostae cinerariaefolium), Eucalyptus camaldulensis Sm. (Myrtaceae) and Nacotiana tabaccum (Tobacco) against the malaria vector Anopheles gambiae s.s. Giles (Diptera: Culicidae).

\begin{tabular}{|c|c|c|c|c|c|c|}
\hline Plant & $\begin{array}{c}\text { Part } \\
\text { used }\end{array}$ & $\begin{array}{c}\text { Extract } \\
\text { solvent }\end{array}$ & LC $C_{50}(\mathrm{ppm})$ fiducial limit & $L C_{90}(\mathrm{ppm})$ fiducial limit & Chi-square & DF \\
\hline Pyrethrum & Leaf & Ethanol & $187.78(179.78-196.53)$ & $268.26(247.89-298.53)$ & 4.5217 & 7 \\
\hline & & Methanol & $222.45(209.85-238.71)$ & $331.68(304.33-371.87)$ & 10.645 & 7 \\
\hline & & DCM & $164.86(161.57-176.28)$ & $255.17(235.79-283.96)$ & 14.258 & 7 \\
\hline & & Hexane & $230.66(214.79-252.67)$ & $364.86(328.04-421.73)$ & 19.5759 & 7 \\
\hline & & Ethyl acetate & $227.56(219.77-269.96)$ & $347.38(317.68-391.95)$ & 19.5759 & 7 \\
\hline & & Aqueous & $247.84(233.37-267.72)$ & $318.56(292.26-356.96)$ & 18.6202 & 7 \\
\hline E. camald Ulensis & Leaf & Ethanol & $210.15(193.88-232.07)$ & $335.58(307.90-376.24)$ & 4.6621 & 7 \\
\hline
\end{tabular}


International Journal of Science and Research (IJSR)

ISSN (Online): 2319-7064

Index Copernicus Value (2013): 6.14 | Impact Factor (2014): 5.611

\begin{tabular}{|c|c|c|c|c|c|c|}
\hline & & Methanol & $197.46(189.61-208.69)$ & $329.68302 .40-369.52$ & 13.256 & 7 \\
\hline & & DCM & $168.65(152.44-176.95)$ & $315.85(292.84-348.10)$ & 10.453 & 7 \\
\hline & & Hexane & $198.56(181.66-220.45)$ & $338.85(310.91-379.91)$ & 9.5033 & 7 \\
\hline & & Ethyl acetate & $260.56(240.77-289.96)$ & $347.38(317.68-391.95)$ & 14.0773 & 7 \\
\hline & & Aqueous & $259.58(239.87-288.87)$ & $390.48(367.25-437.70)$ & 6.7556 & 7 \\
\hline Nicotiana tabaccum & Leaf & Ethanol & $189.58(181.50-298.42)$ & $320.75(294.27-359.41)$ & 3.546 & 7 \\
\hline & & Methanol & $224.35(211.73-240.86)$ & $332.75(305.31-373.07)$ & 3.8642 & 7 \\
\hline & & DCM & $229.72(216.80-246.63)$ & $342.64(313.35-386.59)$ & 15.5740 & 7 \\
\hline & & Hexane & $235.85(221.25-240.53)$ & $314.70(291.77-346.54)$ & 4.6542 & 7 \\
\hline & & Ethyl acetate & $201.52(191.00-213.84)$ & $322.84(296.18-361.75)$ & 14.0773 & 7 \\
\hline & & Aqueous & $258.42(238.79-287.58)$ & $393.36(350.44-462.19)$ & 6.4444 & 7 \\
\hline
\end{tabular}

Three plant leaf extracts (Pyrethrum, Eucalyptus camaldulensis and Nicotiana tabaccum ) against third instar larvae of Anopheles gambiae s.s. Giles, showed significant larvicidal activity at 0.05 level of significance. DCM leaf extract of pyrethrum was the most effective mosquito larvicide which presented the highest percentage (100\%) mortality on $\mathrm{LC}_{50}$ at 164.86 ppm after 24 hours of exposure. Of the determined larvicidal effect of the three plant leaf extracts against third instar larvae of Anopheles gambiae s.s. Giles, LC $_{50}$ values of DCM extracts of pyrethrum and eucalyptus were 164.86 ppm and 168.65 ppm respectively. Notably ethanol extract of pyrethrum had a remarkable lavicidal activity against third instar larvae of An. gambiae s.s. Giles as well than the corresponding solvent of Eucalyptus camaldulensis and Nicotiana tabaccum with $\mathrm{LC}_{50}$ values of $210.15 \mathrm{ppm}$ and $187.58 \mathrm{ppm}$ respectively and exhibiting a mortality of $94.58 \%$ and $88.76 \%$ respectively.

Other than DCM extracts of all plants showing the highest larvicidal activity, the single plant solvent extract ranges of larvicidal activities were observed that the ethanol extract of pyrethrum had higher larvicidal activity (187.78 ppm) then ethanol of Nicotiana tabaccum, methanol of Eucalyptus camaldulensis, hexane of Eucalyptus camaldulensis, ethyl acetate of Nicotiana tabaccum,and ethanol of Eucalyptus camaldulensis in that order with the $\mathrm{LC}_{50}$ values of 189.58 ppm, 197.46 ppm, 198.56 ppm and 201.50 ppm and 210.15 ppm respectively. The results also indicated that the methanol extract of Eucalyptus camaldulensis (197.46 ppm) exhibited higher larvicidal activity than those of pyrethrum (222.45 ppm) and Nicotiana tabaccum (224.35 ppm) achieving mortality of $92.45 \%$ and $90.38 \%$ respectively on 24 hours exposure. The aqueous extract of pyrethrum, Eucalyptus camaldulensis and Nicotiana tabaccum exhibited low larvicidal activities with $\mathrm{LC}_{50}$ values of $247.84 \mathrm{ppm}$, $259.58 \mathrm{ppm}$ and $258.42 \mathrm{ppm}$ respectively enabling mortality of $89.74 \%, 86.56 \%$ and $79.55 \%$ respectively after 24 hours treatment. Control experiment indicated that the mixture of unchlorinated tap water and 1:1 v/v acetone: DMSO did not show any effect on the mortality of third instar larvae of $A n$. gambiae s.s. Giles.

All the three essential oils showed concentration dependent larval mortality. Pyrethrum oil was the most effective treatment.

\section{Discussion}

The findings of the present study suggest that larvicidal attributes of the three essential oils against Anopheles gambiae s.s establishes their potential for control of the mosquito colonies. The $100 \%$ larval mortality of the late third instar larvae of Anopheles gambiae s.s. were observed in pyrethrum DCM extract ( $\mathrm{LC}_{50}$ 164.86ppm, $\mathrm{LC}_{90}$ 255.17ppm), Eucalyptus camadulensis DCM extract ( $\mathrm{LC}_{50}$ 168.65ppm, LC $_{90} 315.85 \mathrm{ppm}$ ) and Nicotiana tabaccum ethanol extract ( $\mathrm{LC}_{50}$ 189.58ppm, $\left.\mathrm{LC}_{90} 320.75 \mathrm{ppm}\right)$. The oils seem to have specific traits which need be manipulated in order to protect human health from vectors of disease. It is reported that more than 2000 plant species are documented to have chemicals with pest control characteristics (Ahmed et al, 1984) (43) and of these 344 species of native plants have been known to possess some level of activity particularly against mosquitoes (Sukumar et al. 1991) (44). Although Anopheles gambiae s.s. has not been tested against pyrethrin and nicotine essential oils, Eucalyptus camaldulensis has been in the past tested on other mosquito species other than Anopheles gambiae s.s. with impressive results (Cheng et al, 2009) (27). Oils tested demonstrated significant larvicidal activity on Anopheles gambiae s.s. larvae ( Cheng et al., 2009; Wada and Singh,2014; Bilal et al., 2012; Alejandro and Masuh, 2008; among others ) $(\mathbf{2 7}, \mathbf{2 3 , 1 7 , 4 8 )}$. Testing the plant crude extracts against mosquito can lead to identifying potential bioactive compounds that can be used as larvicides to control mosquitoes (45 ). It is reported that mosquito programmes can be easily carried out targeting larval stages as they are confined to water bodies which are mainly manmade and can be located (46).

The control test showed no larval mortality on any of the test periods. A gradient of increasing mortality with increasing concentration was observed in all treatments. The higher activity of DCM extract of pyrethrum, Eucalyptus camaldulensis and Nicotiana tabaccum may be due to the presence of bioactive components against third instar larvae of Anopheles gambiaes.s. Giles. Further, semi-polar solvents had ability to dissolve polar and non polar compounds (47). In this case DCM is semi- polar solvent and polar and nonpolar compounds can be dissolved in the DCM crude extracts of all tested plants. Therefore the presence of polar and non-polar active compounds in the DCM extract makes it of higher larvicidal activity than others. This work demonstrates the potency of pyrethrum, Eucalyptus camaldulensis and Nicotiana tabaccum in the control of mosquito larvae and therefore the results obtained suggest that the essential oils are promising as larvicides against Anopheles gambiae s.s. larvae.

\section{Conclusion}

\section{Volume 5 Issue 3, March 2016} www.ijsr.net 


\section{International Journal of Science and Research (IJSR) \\ ISSN (Online): 2319-7064 \\ Index Copernicus Value (2013): 6.14 | Impact Factor (2014): 5.611}

The use of plant essential oils in vector control is an alternative control method for minimizing the effects of persistence, bioaccumulation and toxicity caused by chemical compounds used as insecticides in the environment. In complement to this statement the results obtained suggest that the essential oils are promising as larvicides. Consequently, dichloromethane extract of pyrethrum and Eucalyptus camaldulensis posses higher larvicidal activity than other solvent extracts of the three plants against third instar larvae of Anopheles gambiae s.s. Giles. Therefore, purification of bioactive molecule from the DCM extract of pyrethrum and Eucalyptus camaldulensis is of importance in order to isolate the bioactive components in these oils. Further studies on the larvicidal efficacy of these plant extracts against different vector mosquitoes of human disease are needed.

\section{References}

[1] Finney, D. J. (1971). Probit analysis, $3^{\text {rd }}$ ed. Cambridge: Cambridge University Press. 13

[2] Bryrne, N. (2007) . "Urban malaria risk in sub-Saharan Africa: where is the evidence?" Travel Medicine and Infections Disease, vol. 5, no. 2, pp. 135, 2007.

[3] Cox, C. (2002). Insecticide fact sheet: pyrethrins/Pyrethrum. Journal of Pesticide Reform: Spring 2002. Volume 22, No. 1.

[4] WHO: World Malaria Report 2012: Geneva: World Health Organization.

[5] Lapcharoen, P., Apiwathnasoru, C., Komalamisra, N., Dekumyoy, P., Palakul, K. and Rongsriyan, Y., (2005). Three indigenous Thai medicinal plants for control of Aedes aegyti and Culex quinquefasciatus. Southern Asian J Trop Med Public Health 2005; 36(4): 167175.

[6] Dhar, R., Dawal, H., Gorg, S.S., Basil, F. and Talwar, G.P. (1996). Effect of volatiles from neem and other natural products on gonotrophic cycle and oviposition of Anopheles stephensi and An. culicifacies (Diptera: Culicidae). Journal of Medical Entomology, 33, 195201.

[7] Moore, J.B. and Levy, L.W. (1975). Pyrethrum sources and uses. Part 1. Commercial sources of pyrethrum. In "Pyrethrum Flowers" ( R.H. Nelson, ed ), pp. 1-9. McLaughlin Gormley King Co., Minneapolis, Minnesota.

[8] Sulaiman S. Fadhilina, K. and Hidayatulfathi O. (2007). Evaluation of Pyrethrin formulations on Dengue / Dengue haemorrhagic fever vectors in the laboratory and sublethal effects. Iranian J Arthropod borne Dis, 2007, 1(2): 1-6.

[9] Allan G.G., and Miller T.A., (1990 ). Long-acting pyrethrin formulations. In " Pesticides and alternatives: Innovative chemical and biological approaches to pest control" (J.E. Casida, ed.), pp.357-364. Elsevier Science Publishers, Amsterdam.

[10] Blakely. W.F. (1965). "A Key to the Eucalyptus" (Third edition). Commonwealth of Australia Forestry and Timber Bureau, Canberra.

[11] Benett (2010). The Eldorado of Forestry: The Eucalyptus in India, South Africa and Thailand, 18502000 55, Supplement 18 (2000). 27 - 50.
[12] Glethil D. (2008). The names of plants (4 $\left.4^{\text {th }} \mathrm{ed}\right)$. Cambridge University Press. P. 158. Also in en.wikipedia.org/wiki/Eucalyptus Retrieved 13/10/2011.

[13] Ramar M., Ignacimuthu and Gabriel, Paulraj M. (2014). Biological activity of nine plant essential oils on the filarial vector mosquito, Culex quinquefasciatus SAY. (Insecta: Diptera: Culicidae). International Journal of Research in Biological Sciences 2014; 4(1) ; 1-5.

[14] Ghoshi A., Chowdhury N., and Chandra G. (2012). Plant extract as potential mosquito larvicides. Indian Journal Med. Res 135, May 2012, pp 581 -598.

[15] Medhi S.M., Reza S.D.A., Mahnazi K., Reza A.M., Abbas H., Hassan M.F.V. (2010). Phytochemistry and larvicidal activity of Eucalyptus camaldulensis against malaria vector, Anopheles stephensi. Asian Pacific Journal of Tropical medicine (2010) 841 - 845. doi:10.1016/S1995-7645(10) 6023-9.

[16] Escatin S. and Mariani S. (2014) Evaluating the toxicity of oil lemon encalyptus, Corymbia citriodora (Hook), against larvae of Asian tiger mosquito and notarget fish and larval amphibians. Anales de Biologia 36: 97-105.

[17] 17. Bilal H., Akrain W., Khan H.A.A , Hassan S.A. and Khan I.A. (20120. Toxicity of selected indigeneous plant extracts against Aedes albopictus (Diptera: Culcidal): A potential Dengue vector in Dengue positive areas. Pakistan J. Zool., Vol. 44(2), pp 371-375, 2012.

[18] Taher E., Narmeen Mahmone N. and Mahmoud M. (2012). Laboratory evaluation of the effect of Egyptian native plants against some parasitic vectors. Turkiye Parazitol Derg 2012; 36: 160-5.

[19] Bossou, A.D., Mangelinckx S.. Hounnankpon Y., Pelagie, M.B., Martin C.A. Kimpe D.N., Arlessi F. and Sohounhloue D.C.K.. (2013). Chemical composition and insecticidal activity of plant essential oils from Benin against Anopheles gambiae (Giles). Parasites and Vectors 2013, 6: 337 doi:10:1186/1756-3303-6-33.

[20] Narendhiran S., Mohanasundaram S., Arun J., Saravanan L., Catherine L., Subathra, M. and Rannjith R.V. (2014). Comparative study in larvicidal efficacy of medicinal plant extracts against Culex quinquefasciatus. International Journal of Research in plant science 2014; 4 (1): 22-25.

[21] Pankaj T. and Anita S. (2014). An endevour to control Anopheles Stephensi (Liston) larvae by plant extracts. Trends in Biosciences 2014, volume 7 issue 23 Tobacco (Nicotiana tabacuum)

[22] Uthayarasa K., Surendaran S.N., Pathmanathan, M.K, Jeyadevan J.P. (2010). Larvicidal efficacy of crude extracts of Emblica officinalis and Eucalyptus citriodora against Aedes aegypti. International Journal of Pharmaceutical and Biological Archives 2010; 1(4) $467-472$.

[23] Wada A., and Singh K. (2014). Larvicidal effects of Eucalyptus camaldulensis plant leaf extract on Culex quinquefasciatus mosquito. European Journal of Pharmaceutical and Medical Research 2014, 1(1); 192 $-203$.

[24] Karthekeyan V., Sivakumar, K., Gokuldass A. and Mohanasundaran. S. (2012). Studies on larvicidal 


\section{International Journal of Science and Research (IJSR) \\ ISSN (Online): 2319-7064 \\ Index Copernicus Value (2013): 6.14 | Impact Factor (2014): 5.611}

activity of Lucas aspera, Vivex negundo and Eucalyptus against Culex quinquefasciatus collected from Coovum river of Chennai, India. Asian. Journal of Pharmaceutical and Clinical Research Vol. 5 suppl 3, 2012.

[25] Hazrat B., Waseem A., Hafic, A.A. K., Soaib A.H. and Imtinan A.K. (2012). Toxicity of selected indigeneous plant extracts against Aedes albopictus (Diptera: culicidae): A potential Dengue vector in dengue positive areas. Pakistan J. Zool. 44(2), pp. 371 - 375, 2012.

[26] Pugazhvendan S.R. and Elumal K. (2013). Larvicidal activity of selected plant essential oil against vector mosquitoes: Denque Vector, Culex quinquefasciatus (Say (Diptera: Culicidal. Middle East Journal of Scientific Research 18(1): 91-95, 2013.

[27] Cheng S.S., Chen, C.G.Y., Yu, J.J., Chen, W.J. and Chang, S.T. (2009). The mosquito larvicidal activity of leaf essential oils and their constituents from two eucalyptus species (Eucalyptus camaldulensis and Eucalyptus wrophylla) against two mosquito species Aedes aegypti and Aedes albopictus. Bioresource Technology 100 (2009):452-456.

[28] Savitha S. N., Vinaya S. and Nadikere J. S. (2014). Relative toxicity of leaf extracts of Eucalyptus globulus and Centella asiatica mosquito vectors Aedes aegypti and Anopheles stephensi. Journal of Insects Volume 2014 (2014), Article ID 985463, 7 pages.

[29] Sengottyan Senthil Nathan (2007). The use of Eucalyptus tereticornis Sm. (Myrtaceae) oil (leaf extract) as a natural larvicidal agent against the malaria vector Anopheles stephensi Liston (Diptera: Culicidal). Bioresource Technology 98/2007) 1856-1860.

[30] 30.http://www.lycos.com/info/tobacco-plants; retrieved March4, 2015.

[31] 31.http://en.wikipedia.org/wiki/tobacco\#citeref1;retrieved March 4, 2015.

[32] http://en.wikipedia.org/wiki/Tobacco\#cite-ref1; retrieved March 4, 2015.

[33] Olofintoye L.K., Simon - Oke S. I. and Omoregie O.B. (2011). Larvicidal properties of Datura, stramonium (Jimson weed) and Nicotiana tabaccum (Tobacco) extracts against the larval of (Anopheles and Culex) mosquitoes. An International Multi-disciplinary Journal, Ethiopia vol. 5(2), Serial No. 19, April 2011 pp. 337-355. Also in Global Journal of Medical Sciences vol. 5, No. 2 (2011).

[34] Puripattanavong, J., Songkram C., Lomlim L. and Amnuaikit T. (2013). Development of concentrated emulsion containing Nicotiana tabaccum extract for use as pesticide. Journal of Applied Pharmaceutical Science Vol. 3 (11), pp. 016 - 021, November, 2013.

[35] Ru Q.M., Wang L.J., Li W.M., Wang J.L. and Ding Y.T. (2012). In-vitro antioxidant properties of flavonoids and polysaccharides extract from tobacco (Nicotiana tabaccum L.) leaves. Molecules 2012, 17, 11281-11291: doi:10.3390/molecules 17091 - 1281.

[36] Priyanka C. S., Chandhari S.V., Sampada J., , Shinde J.S. and Sneha W. (2013). Herbal control of mosquito larvae. Int. J. Bioassays, 2013, 02 (05), 794 - 798.

[37] Kabil K.E., Khan A.R. and Mosaddik M.A (2003). Goniothalamin - A potent mosquito larvicide from
Bryonopsis laciniosa L. Journal of Applied Entomology, 127, 112 - 115. doi:10.1046/j/1439-0418.

[38] McAllister, J.C., and Adams, M.F. (2010). Modes of action for natural products isolated from essential oils of two trees is different from available mosquito adulticides. J Med Entomol 2010 Nov; 47(6): 1123-6.

[39] Dharmagadda V.S.S, Naik S.N., Mittal P.K. and Vasudevan, P. (2005). Larvicidal activity of Tegets patula essential oil against three mosquito species. Biores. Technol. 96, 1235 - 1240.

[40] World Health Organization (1981). Instruction for determining the susceptibility or resistance of mosquito larvae to insecticide. WHO/VBC/81.807.

[41] WHO, (2005) : Guidelines for laboratory and field testing of mosquito larvicides. WHO/CDC/WHOPES/GCDPP/2005.13

[42] Abbott's W.S. (1925). A method of computing the effectiveness of an insecticide. J. Econ. Entomol. Riverside, Vol.18 no. 2 ; 265-267, 1925.

[43] Ahamed, SGM., Hylin JW., Mitchell, WC., and Litsinger, JA., (1984). Investigating the feasibility of using botanical materials for pests control under traditional farming system: A suggested neem approach. Proc. $2^{\text {nd }}$ International Neem Conference , Rauischolzhausen, pp 545-550.

[44] Sukumar, K. ,Perch, M.J., and Boobar, L.R. (1991). Botanical derivatives in mosquito control. J. Am. Mosq. Control Assoc., 7(1991), pp210-237.

[45] Anarajeewa BWR, Mudaligie AP, and Kumar V (2007). Chemistry and mosquito larvicidal activity of Gnidia glauca. Proceedings of the Peradeniya University Research Sessions, Sri Lanka 2007; 12(1): 101-102.

[46] Srivastava A., Bartaya R.,Tonks S, Srivastava S.S., and Kumari M. (2008). Larvicidal activity of an indigenous plant, Centratherum anthelminticum. J Environ Biol 2008; 29(5): 669-672.

[47] Asghavi G., Nouralliahi H., Havaie S.A.and Issa L. (2006). Antimicrobial activity of Otostegia persica Boiss. extracts. Res Pham Sci. 2006; 1: 53-58.

[48] Alejandro and masuh, (2008). Yield, chemical composition and bioactivity of essential oils from 12 species of Eucalyptus on Aedes aegypti larvae. Entomol Exp Appl 10/2008; 129(1): 107-114. DOI:10.1111/j1570-7458.2008.00757x 